\title{
Human Ro Ribonucleoprotein Particles: Characterization of Native Structure and Stable Association with the La Polypeptide
}

Gilles Boire and Joe Craft

Section of Rheumatology, Department of Medicine, Yale University, New Haven, Connecticut 06510

\begin{abstract}
Anti-Ro autoantibodies, found in sera of patients with systemic lupus erythematosus, Sjogren's syndrome, and related diseases, target the Ro ribonucleoprotein particles (RNPs). Although the polypeptide and RNA components of the Ro RNPs have been characterized, much less is known about the native structure of these particles. We have now characterized by biochemical techniques intact $R o$ ribonucleoprotein particles from cultured HeLa cells. These particles segregated in three discrete subpopulations with characteristic physicochemical properties: one containing hY5 RNA (Ro ${ }^{\text {hY5 }}$ particles), one containing only hY4 RNA (Ro ${ }^{\text {hY4 }}$ particles) and one with hY1, hY3, and hY4 RNAs (Ro ${ }^{\text {hY1-hY4 }}$ particles). The Ro ${ }^{\text {hY5 }}$ particles were purified free of contaminating ribonucleoproteins; both the $\mathrm{La}$ and the 60-kD Ro polypeptides were stable components of this portion of the Ro RNPs. The La RNPs co-purified with the $\mathrm{Ro}^{\mathrm{hY4}}$ particles and contaminated the Ro ${ }^{\mathrm{hY1} 1 \mathrm{hY} 4}$ RNPs. The stable association between the $\mathrm{La}$ and the $60-\mathrm{kD}$ Ro polypeptides provides a potential macromolecular target for the linked set of anti-Ro and anti-La antibodies, and suggests a possible functional association of these polypeptides. (J. Clin. Invest. 1990. 85:1182-1190.) autoantibodies • anti-Ro antibodies $\bullet$ ribonucleoproteins $\bullet$ Ro protein $\bullet$ La protein
\end{abstract}

\section{Introduction}

Autoimmune diseases such as systemic lupus erythematosus (SLE) are characterized by autoantibodies in patient sera that bind highly conserved autoantigens (reviewed in 1-3). The spectrum of this autoimmune response is often restricted in any given patient $(3,4)$, with certain autoantibody specificities that correlate with clinical manifestations (reviewed in 1-3). Thus many efforts have been made to define the structural or biological features of autoantigens that might nominate them as targets of autoimmunity (for examples, see 5-8).

Anti-Ro antibodies are a prominent feature of the humoral autoimmune response in many patients with SLE and with Sjogren's syndrome $(9,10)$. These antibodies target small ribo-

Published in abstract form in 1989. (Arthritis Rheum. 32:S118.)

Address reprint requests to Dr. Craft, Department of Medicine, Yale University School of Medicine, Box 3333, 609 LCI, New Haven, CT 06510.

Dr. Boire's permanent address is Division of Rheumatology, Department of Medicine, Centre Hospitalier Universitaire de Sherbrooke, 3001-12th Ave. North, Sherbrooke, Quebec, Canada J1H $5 \mathrm{~N} 4$.

Received for publication 18 July 1989 and in revised form 27 November 1989.

J. Clin. Invest.

(c) The American Society for Clinical Investigation, Inc.

$0021-9738 / 90 / 04 / 1182 / 09 \$ 2.00$

Volume 85, April 1990, 1182-1190 nucleoprotein particles (RNPs) ${ }^{1}$ that consist of a $60-\mathrm{kD}$ Ro polypeptide associated with $2-4$ small RNAs $(11,12)$. Recent evidence also indicates that a 52-kD polypeptide, and a 54-kD polypeptide restricted to erythrocytes, are complexed with the Ro RNAs $(13,14)$. The number of RNAs differs among mammalian cells: for example, human cells contain four Ro RNAs, called hY1, hY3, hY4, and hY5, and murine cells contain two such RNAs, $\mathrm{mY} 1$ and $\mathrm{mY2}(15)$. These RNAs are RNA polymerase III transcription products, and as such, are at least transiently associated with the La polypeptide (11). The 60-kD Ro polypeptide binds its Ro RNA at the base of a double-stranded stem formed by base-pairing of $5^{\prime}$ and $3^{\prime}$ ends (12); the binding site of the La polypeptide is believed to be at least partially constituted by a poly (U) stretch at the $3^{\prime}$ end of the RNA that is processed to form the mature Ro RNA transcript with release of this polypeptide (16-18). The RNA and/ or protein binding sites for the 52- and 54-kD Ro polypeptides have yet to be defined.

Indirect evidence indicates that one 60-kD Ro polypeptide binds to one Ro RNA (12), implying the existence of distinct populations of Ro RNPs. We recently reported the frequent occurrence in patient sera of antibodies that targeted an antigenic epitope restricted to intact Ro particles containing the 60-kD Ro polypeptide and the hY5 RNA (Ro ${ }^{\text {hY5 }}$ RNPs) (19). The production of antibodies to a specific Ro RNP suggested structural heterogeneity of these particles; moreover, the production of antibodies that only recognized intact $\mathrm{Ro}^{\mathrm{hYS}}$ particles indicated that native Ro RNPs might serve as autoimmunogens, in addition to (or rather than) isolated Ro polypeptides.

Thus, to determine if Ro particles are indeed physically heterogeneous, and to identify structural features that could possibly designate a subset of these native Ro particles as targets of a specific autoimmune response, we have biochemically purified intact human Ro particles containing the $60-\mathrm{kD}$ Ro polypeptide and the Ro RNAs. These particles segregated in three subpopulations with characteristic physicochemical properties. The La polypeptide, frequently targeted by the autoimmune response in conjunction with the Ro polypeptides, was stably associated with a portion of these purified particles.

\section{Methods}

Cells and sera. Human HeLa cells, initially obtained from American Type Culture Collection (Rockville, MD), were maintained at $37^{\circ} \mathrm{C}$ under $5 \% \mathrm{CO}_{2}$, in RPMI 1640 (Gibco Laboratories, Grand Island, NY) supplemented with $10 \%$ heat-inactivated fetal calf serum, $60 \mu \mathrm{g}$ of penicillin $/ \mathrm{ml}$ and $100 \mu \mathrm{g}$ of streptomycin $/ \mathrm{ml}$. Sera were obtained from healthy laboratory workers and from American and French Canadian patients with various connective tissue diseases. Control anti-Ro sera

1. Abbreviations used in this paper: RNP, ribonucleoprotein particles; TBS, Tris-buffered saline; TSE, Tris- $\mathrm{Cl}, \mathrm{NaCl}$, and EDTA. 
were defined as those which immunoprecipitated the 60-kD Ro polypeptide and all four hY RNAs from radiolabeled HeLa cell extracts (19), while anti-Ro ${ }^{\mathrm{hY} 5}$ sera immunoprecipitated only the $60-\mathrm{kD}$ polypeptide and the hY5 RNA from identical extracts (19). The anti-Ro sera used did not immunoprecipitate the La RNAs from HeLa cell extracts nor recognize the 50-kD La polypeptide in immunoblots. As previously reported (12), a protein that comigrated with the La polypeptide was faintly visible in $\left[{ }^{35} \mathrm{~S}\right]$ methionine labeled anti-Ro immunoprecipitates. None of the sera used in these studies immunoprecipitated the 52-kD Ro polypeptide from HeLa cell extracts, nor recognized this protein in immunoblots of these extracts (13).

Preparation and immunoprecipitation of cell extracts. For analysis of in vivo labeled RNAs, HeLa cells were radiolabeled with [ $\left.{ }^{32} \mathrm{P}\right]$ orthophosphate $(10 \mu \mathrm{Ci} / \mathrm{ml}$ cells; Amersham Corp., Arlington Heights, IL) for $14 \mathrm{~h}$ as previously described (20). Cells were collected by centrifugation, washed in TBS (10 mM Tris- $\mathrm{Cl}$ [7.5], $150 \mathrm{mM} \mathrm{NaCl})$, and sonicated in NET-2 buffer ( $50 \mathrm{mM}$ Tris-Cl [7.5], $150 \mathrm{mM} \mathrm{NaCl}, 0.05 \%$ Nonidet P-40). Immunoprecipitation of radiolabeled and unlabeled cell extracts was performed as described (19). Immunoprecipitated ${ }^{32} \mathrm{P}$-labeled nucleic acids were visualized by autoradiography on XRP film (Eastman Kodak, Rochester, NY) while the unlabeled RNAs were visualized by silver staining (21). For analysis of proteins, HeLa cells were labeled with $\left[{ }^{35} \mathrm{~S}\right]$ methionine $(10 \mu \mathrm{Ci} / \mathrm{ml}$ cells; Amersham Corp.) and immunoprecipitations performed as described (19).

In experiments to assess the stability of the association of hY RNAs with the 60-kD Ro polypeptide, $4 \mathrm{M} \mathrm{NaCl}$ was added to parallel samples of the HeLa cell sonicates to increase their salt concentration to $0.25,0.35,0.50,0.75$, and $1.00 \mathrm{M}$, respectively. After rotation for $1 \mathrm{~h}$ at $4^{\circ} \mathrm{C}$, these samples with high salt concentrations were added to antibody-coated Sepharose beads resuspended in NET-2 buffer that had been previously modified to contain the same $\mathrm{NaCl}$ concentrations as the sonicates.

Biochemical purification of the Ro particles. The first steps of the purification of the Ro particles were performed as described (19), with modifications. In brief, 1-2 $\times 10^{9} \mathrm{HeLa}$ cells were collected by centrifugation and washed twice in chilled TBS. Subsequently all procedures were performed at $4^{\circ} \mathrm{C}$ and all buffers were supplemented with $1 \mathrm{mM}$ dithiothreitol and $1 \mathrm{mM}$ phenylmethylsulfonyl fluoride. A cytoplasmic fraction was prepared without detergent: cells were allowed to swell in six pellet-volumes of buffer A (10 mM Tris-Cl [7.5], $1.5 \mathrm{mM}$ $\mathrm{MgCl}_{2}, 10 \mathrm{mM} \mathrm{KCl}$ ) for $10 \mathrm{~min}$ on ice, spun down, resuspended in two pellet-volumes of buffer $\mathrm{A}$ and disrupted by 10 strokes of an all-glass Dounce homogenizer; $100 \mathrm{U}$ of RNAsin (Promega Biotec, Madison, WI) were added after disruption of the cells. Extracts were then clarified by centrifugation at $13,000 \mathrm{~g}$ for $20 \mathrm{~min}$. The salt concentration of the supernatant was increased to $140 \mathrm{mM}$ by adding 0.1 vol of buffer $B$ (0.3 M Tris-Cl [7.5], 1.4 M NaCl, $\left.1.5 \mathrm{mM} \mathrm{MgCl}_{2}\right)$. The extract was then layered over a $7.5-\mathrm{ml}$ sucrose cushion $(800 \mathrm{mM}$ sucrose, $10 \mathrm{mM}$ Tris-Cl [7.5], $5 \mathrm{mM} \mathrm{MgCl}$ ) in 30-ml tubes and centrifuged at 26,000 rpm in a SW28 rotor (Beckman Instruments, Inc., Palo Alto, CA) for $90 \mathrm{~min}$. The supernatant was collected and diluted 1:1 with TSE (50 mM Tris-Cl [7.5], $150 \mathrm{mM} \mathrm{NaCl}, 1 \mathrm{mM}$ EDTA) and applied to a 40-ml column of DE52 (Whatman, Maidstone, Kent, England) preequilibrated in TSE. After extensive washings with TSE, step elutions of the column using TSE containing $175,190,210,250$, and $300 \mathrm{mM}$ $\mathrm{NaCl}$ were performed. After addition of $40 \mathrm{U}$ of RNAsin, each eluate was separately concentrated by vacuum dialysis (Pro-Di-Con; Bio-Molecular Dynamics, Beaverton, OR) against TSE. Elution profiles of the Ro RNPs in each of the eluted fractions were determined by immunoprecipitation with control anti-Ro sera.

The concentrated DE52 eluates $(0.5 \mathrm{ml})$ containing the different Ro particles were each layered on a $10-30 \%(w t / w t)$ sucrose gradient $(10.5 \mathrm{ml})$ and centrifuged at $35,000 \mathrm{rpm}$ in an SW41 rotor (Beckman Instruments, Inc.) for $18 \mathrm{~h}$. After centrifugation, serial 0.5 -ml fractions were collected from the bottom of the tube and assayed by immunoprecipitation for the presence of Ro particles. The fractions containing the peaks of the Ro RNPs were further fractionated by HPLC in TSE at room temperature on a gel permeation column (TSK G3000 SW 600 $\times 7.5 \mathrm{~mm}$; Phenomenex, Rancho Palos Verdes, CA) at a flow rate of $0.5 \mathrm{ml} / \mathrm{min}$ (260 psi). Molecular weight standards included thyroglobulin (669 kD), ferritin (440 kD), catalase (232 kD), aldolase (158 kD), bovine serum albumin (67 kD), chymotrypsinogen A (25 kD), and uridine $(0.244 \mathrm{kD})$. The eluates were collected in $250-\mu \mathrm{l}$ fractions and assayed by immunoprecipitation for the presence of Ro particles.

SDS-polyacrylamide gel electrophoresis and immunoblotting. Proteins present in extracts at each step of the purification were either concentrated in Centricon-30 cones (Amicon Corp., Danvers, MA), or precipitated in $25 \%$ TCA, spun down by centrifugation at $12,000 \mathrm{~g}$ for $15 \mathrm{~min}$, the pellet washed twice in cold acetone, and dried. Proteins were then dissolved in SDS-sample buffer (63 mM Tris-Cl [6.8], 2\% SDS, $2 \%$ 2-mercaptoethanol, $20 \%$ glycerol, $0.004 \%$ bromophenol blue) before fractionation in SDS-7.5\% polyacrylamide gels (22) (acrylamide/bis, 30:0.8). $4 \mu \mathrm{g}$ per lane of $60-\mathrm{kD}$ Ro polypeptides affinity-purified from human placenta (kindly provided by Dr. M. Mamula, Yale University School of Medicine) were fractionated as a positive control on each gel. After transfer to nitrocellulose (Schleicher and Schuell, Keene, NH) in $25 \%$ methanol, Tris-glycine [8.3] (23), the nitrocellulose sheets were blocked with 3\% BSA in TBS overnight and subsequently incubated with human antisera diluted 1:50 in TBS containing $0.1 \%$ Tween 20 and $1.0 \%$ BSA. Bound antibodies were detected with ${ }^{125}$ I-labeled protein A $\left(1 \times 10^{5} \mathrm{cpm} / \mathrm{ml}\right.$; ICN, Irvine, CA $)$ followed by autoradiography on XRP film (Kodak).

Affinity purification of antibodies. Anti-La antibodies were affinity-purified (24) from a serum containing high titers of anti-La antibodies and a paucity of anti-Ro antibodies, as determined by immunoblotting assays. The La polypeptide from a sonicate of total HeLa cells was localized on immunoblots; the corresponding area was then cut out, incubated with the anti-La serum, and extensively washed. The bound antibodies were eluted with $0.2 \mathrm{M}$ glycine- $\mathrm{HCl}$ [2.5], neutralized with $2 \mathrm{M}$ Tris- $\mathrm{Cl}$ [7.5], and assayed by immunoprecipitation. Control antibodies eluted from an unrelated strip of the nitrocellulose sheet lacked anti-La activity in the ${ }^{32} \mathrm{P}$ immunoprecipitation assay $(19,20)$.

\section{Results}

The Ro RNAs dissociate from the Ro particles at high ionic strength. To define the conditions of purification compatible with isolation of native Ro particles, we verified the stability of the Ro particles in buffers of increasing ionic strength. As shown in Fig. $1 A$, relatively low salt concentrations dissociated the Ro RNAs from the $60-\mathrm{kD}$ Ro polypeptides. Anti-Ro sera specific for the $60-\mathrm{kD}$ polypeptide could not immunoprecipitate Ro RNAs from extracts containing $500 \mathrm{mM} \mathrm{NaCl}$ (Fig. $1 \mathrm{~A}$, compare lanes 3 and 6 ). This did not result from the loss of binding of anti-Ro antibodies to the polypeptide itself, since the intensity of the $60-\mathrm{kD}$ band immunoprecipitated from $\left[{ }^{35} \mathrm{~S}\right]$ methionine labeled cell extracts did not decrease in buffers containing up to $1 \mathrm{M} \mathrm{NaCl}$ (Fig. $1 \mathrm{~B}$; compare lane 2 to lane 3). The sensitivity to dissociation in buffers of high ionic strength varied among the Ro RNPs: hY3 and hY4 were totally dissociated from Ro polypeptides in $350 \mathrm{mM} \mathrm{NaCl}$, while hY1 and hY5 were only partially dissociated in the same salt concentration (Fig. $1 A$, lane 4 ). The presence of low millimolar concentrations of EDTA in the buffers appeared to slightly stabilize the Ro RNA-protein bond (data not shown), thus all buffers used in the purification procedure contained $1 \mathrm{mM}$ EDTA.

Dissociation in these salt concentrations is a characteristic of Ro particles, since the immunoprecipitation of the La RNAs by anti-La sera was not affected in up to $750 \mathrm{mM} \mathrm{NaCl}$ (Fig. $1 \mathrm{~A}$; compare lane 7 to lane 8 ). It is interesting that under conditions where the Ro RNAs have dissociated from the 


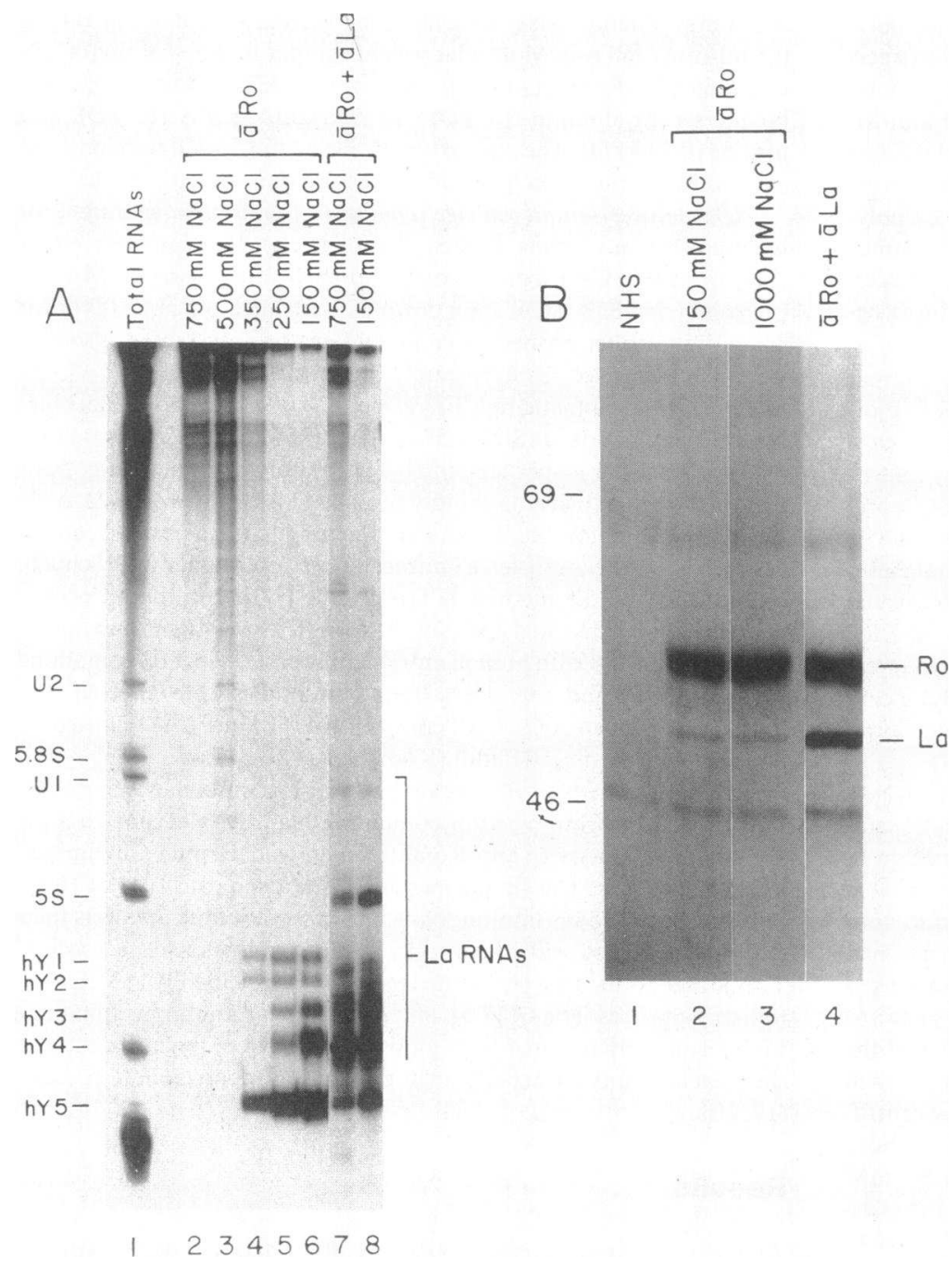

Figure 1. Immunoprecipitation of Ro RNPs from HeLa cell extracts in increasing salt concentrations. $(A)$ Immunoprecipitation of ${ }^{32} \mathrm{P}$-labeled extracts with an anti-Ro serum (lanes 2-6) and with a serum containing anti-Ro and anti-La antibodies (lanes 7 and 8). Immunoprecipitations were performed in NET-2 buffer modified with $4 \mathrm{M} \mathrm{NaCl}$ in order to obtain a final concentration of $0.15 \mathrm{M}$ (lanes 6 and 8 ), $0.25 \mathrm{M}$ (lane 5), $0.35 \mathrm{M}$ (lane 4), $0.50 \mathrm{M}$ (lane 3) and $0.75 \mathrm{M}$ $\mathrm{NaCl}$ (lanes 2 and 7). Lane 1 represents RNAs present in total cellular extracts. (B) Immunoprecipitation of $\left.{ }^{35} S\right]$ methionine labeled extracts with a normal human serum (NHS; lane 1), with an anti-Ro serum (lanes 2 and 3 ) and with a serum containing both anti-Ro and anti-La antibodies (lane 4). The immunoprecipitations were performed in NET-2 buffer containing $150 \mathrm{mM} \mathrm{NaCl}$ (lanes 1,2 , and 4) and containing $1 \mathrm{M} \mathrm{NaCl}$ (lane 3 ). The positions of the 60-kD Ro and the 50-kD La polypeptides are indicated. A band corresponding to the 52-kD Ro polypeptide (13) was not immunoprecipitated with these sera. The bands at 45 and $65 \mathrm{kD}$ are not specific since they appear in the immunoprecipitate formed with the normal control serum. Molecular weight markers were ${ }^{14} \mathrm{C}$-methylated bovine serum albumin $(69 \mathrm{kD})$ and ${ }^{14} \mathrm{C}$-methylated ovalbumin (46 kD).
60-kD Ro polypeptide, an anti-La serum still immunoprecipitated an RNA co-migrating with hY5; however, bands corresponding to hY1 and hY2 (a breakdown product of hY1) have disappeared (Fig. $1 A$; compare lane 7 to lane 8 ).

Three subpopulations of Ro particles can be biochemically purified from HeLa cells. As reported by Kato et al. (25), more than $90 \%$ of the Ro particles were recovered in the cytoplasmic fraction of HeLa cells prepared by gentle cell disruption, even without detergent (data not shown). The cytoplasmic fraction was then loaded on a DE52 anion exchange column, washed extensively, and the bound material eluted stepwise with buffers of increasing ionic strength. As illustrated in Fig. 2, and as previously reported (19), the $\mathrm{Ro}^{\mathrm{hY} 5}$ particles were present in both the $175 \mathrm{mM}$ and $190 \mathrm{mM} \mathrm{NaCl}$ eluates (lanes 3 and 4, lanes 10 and 11 ), a group of particles containing all four Ro RNAs ( $\mathrm{Ro}^{\mathrm{hY} 1-\mathrm{hYS}}$ particles) eluted between $210 \mathrm{mM}$ and 250 $\mathrm{mM} \mathrm{NaCl}$ (lanes 6 and 13), and Ro particles containing hYl, hY3, and hY4 RNAs (Ro ${ }^{\text {hY1-hY4 }}$ particles), but nearly devoid of any hY5 RNA, eluted between 250 and $300 \mathrm{mM} \mathrm{NaCl}$ (lanes 7 and 14). The Ro RNAs in each of these fractions were immunoprecipitated with an anti-Ro serum that bound the 60-kD Ro polypeptide (lanes 10-14), indicating that this polypeptide was complexed with its cognate RNAs. Contaminating tRNA and 5S RNA were present in each of the three fractions; however, it was noteworthy that the hY5 RNA and the La RNAs constituted major RNA species in the 175 and $190 \mathrm{mM}$ and in the 210 to $250 \mathrm{mM} \mathrm{NaCl}$ eluates, respectively (Fig. 2, lanes 3 and 4, and lane 6). From these elution experiments, it was evident that Ro particles existed as at least two populations: the $\mathrm{Ro}^{\mathrm{hY} 5}$ RNPs, and the Ro ${ }^{\mathrm{hY} 1, \mathrm{hY} 3, \mathrm{hY} 4}$ RNPs. The existence of a third population of particles, one that contained all four Ro RNPs (Ro ${ }^{\text {hY1-hY5 }}$ ) and that eluted between 210 and $250 \mathrm{mM} \mathrm{NaCl}$ could simply result from a contamination with each of the other two populations; alternatively, it could represent a group of Ro particles containing the Ro RNAs in approximately equimolar ratios.

After concentration to $\sim 500 \mu \mathrm{l}$, the three eluates were loaded separately onto $10-30 \%$ (wt:wt) sucrose gradients and fractionated by rate zonal ultracentrifugation. The $\mathrm{Ro}^{\mathrm{hY} 5}$ RNPs, eluted at $175 \mathrm{mM} \mathrm{NaCl}$ from DE52, sedimented as a single peak where the major contaminating RNA was 5S RNA (Fig. $3 \mathrm{~A}$, lane 6); in the peak fraction, 5S RNA was not immunoprecipitable with anti-La antibodies (data not shown). In the $250 \mathrm{mM} \mathrm{NaCl}$ DE52 eluate, the Ro RNPs appeared to sediment slightly ahead of the La RNPs (Fig. $3 \mathrm{~B}$, compare lanes 5 and 6 to lanes 7 and 8 ). This observation was confirmed by immunoprecipitations of individual gradient fractions with an anti-Ro serum and with an anti-La serum as 


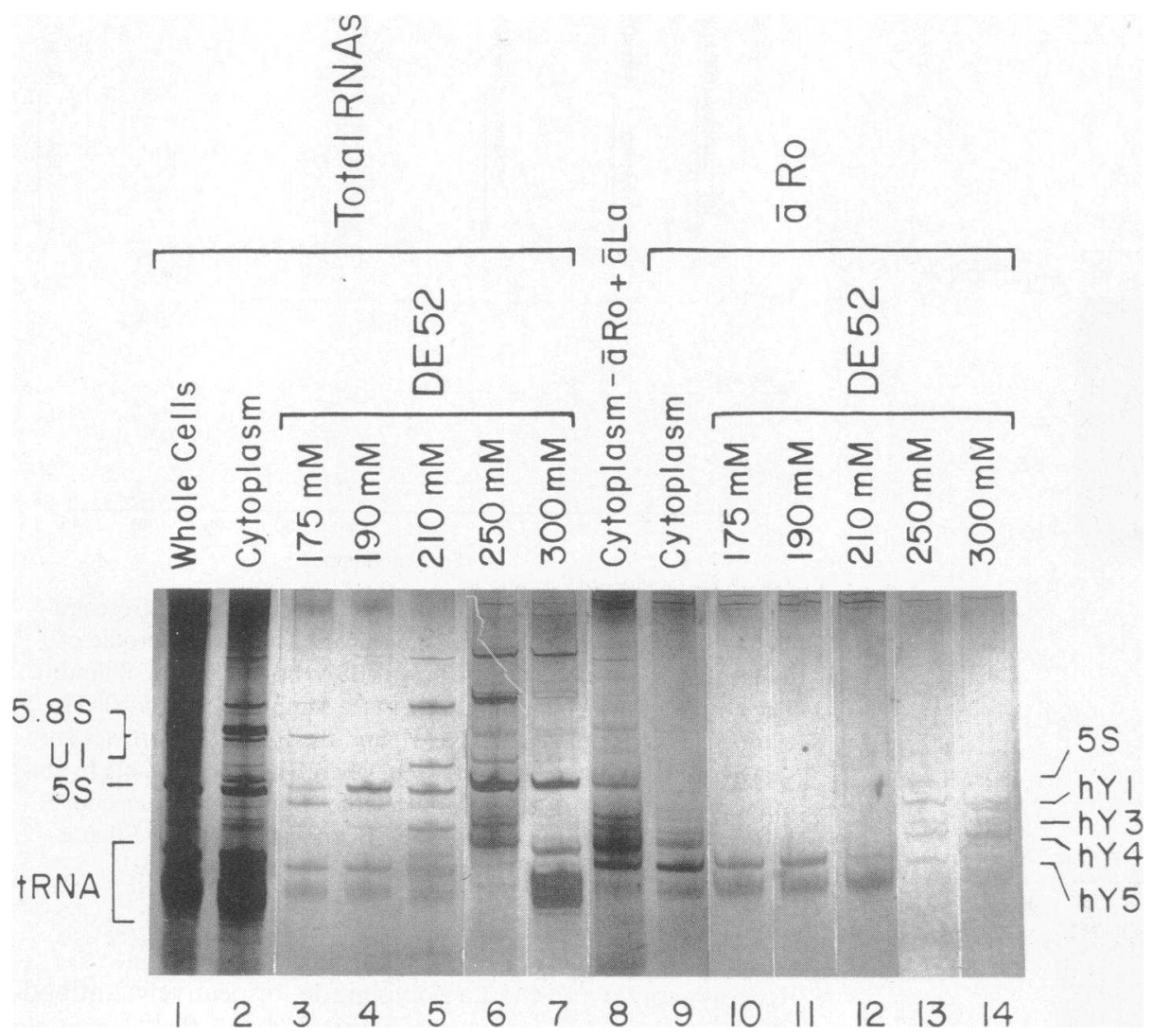

Figure 2. Ro particles after fractionation with DE52 anion exchange chromatography. Total RNAs are shown in lanes $1-7$. To help identify the fractionated RNAs, immunoprecipitates formed with an antiRo plus anti-La serum (lane 8 ) and an anti-Ro serum (lanes 9-14) are also shown. Lane 1 , RNAs in total cellular extract; lanes 2,8 , and 9 , RNAs in cytoplasmic fraction; lanes 3 and $10,175 \mathrm{mM}$ eluate; lanes 4 and $11,190 \mathrm{mM}$ eluate; lanes 5 and $12,210 \mathrm{mM}$ eluate; lanes 6 and 13 , $250 \mathrm{mM}$ eluate; lanes 7 and 14,300 $\mathrm{mM}$ eluate. shown in Fig. $3 C$ (note that the peak of immunoprecipitable Ro RNPs was in fractions 14 and 15 , whereas the peak of immunoprecipitable La RNPs was in fractions 16 and 17). A population of $\mathrm{Ro}^{\mathrm{hY} 4} \mathrm{RNPs}$ did sediment with the peak of the La RNPs (Fig. $3 C$, lanes 4 and 9), however, indicating that $\mathrm{Ro}^{\mathrm{hY} 4}$ particles could represent a third discrete subpopulation of Ro RNPs, in addition to $\mathrm{Ro}^{\mathrm{hY} 5}$ RNPs and a population that appeared to contain the hY1-hY4 RNAs (Ro $\left.{ }^{\mathrm{hY} 1-\mathrm{hY} 4} \mathrm{RNPs}\right)$. The displacement of the $\mathrm{Ro}^{\mathrm{hY} 4}$ particles from the other Ro RNPs was not secondary to in vitro dissociation of the hY4 RNA from the antigenic $60-\mathrm{kD}$ Ro polypeptide since these RNPs could be immunoprecipitated by a serum that targeted the $60-\mathrm{kD}$ protein.

The peaks of Ro particles from the sucrose gradients were further fractionated by gel filtration HPLC. Again, $\mathrm{Ro}^{\mathrm{hY} 4}$ particles behaved differently from the other Ro RNPs (Fig. 4). While the Stokes' radius of the $\mathrm{Ro}^{\mathrm{hY} 5}$ particles and the $\mathrm{Ro}^{\mathrm{hY} 1-\mathrm{hY} 4}$ particles appeared compatible with the elution profile of a globular protein of $300-350 \mathrm{kD}$, the $\mathrm{Ro}^{\mathrm{hY} 4}$ particles eluted at $\sim 230 \mathrm{kD}$ (Fig. 4) with the bulk of the La particles (data not shown), consistent with their cosedimentation in sucrose gradients. After HPLC purification of the $\mathrm{Ro}^{\mathrm{hY} 5}$ RNP fraction from sucrose gradients, hY5 RNA represented the predominant RNA visible in silver-stained gels of phenol/ chloroform extracts of the peak eluates (Fig. $5 \mathrm{~A}$, lanes 4 and $5)$, although several polypeptides were present in these fractions (Fig. $5 \mathrm{~B}$, lanes 5 and 6). The peak fractions of the $\mathrm{Ro}^{\mathrm{hY} 1-\mathrm{hY} 4}$ particles and of the $\mathrm{Ro}^{\mathrm{hY} 4}$ particles were still heavily contaminated with La RNPs; in these fractions, the Ro and La RNAs were not degraded (data not shown).

Characterization of the purified Ro particles. After each purification step, the Ro RNAs were immunoprecipitated with
anti-Ro sera specific for the $60-\mathrm{kD}$ Ro polypeptide. This implied that this protein remained bound to the immunoprecipitated Ro RNAs through the final stages of purification. To investigate this possibility, we performed immunoblots using anti-Ro, as well as anti-La sera, of the peaks of the HPLC eluates containing the $\mathrm{Ro}^{\mathrm{hY} 5}$, the $\mathrm{Ro}^{\mathrm{hY} 1-\mathrm{hY} 4}$, and the $\mathrm{Ro}^{\mathrm{hY} 4}$ RNPs, respectively. Both the $60-\mathrm{kD}$ Ro polypeptide (Fig. 6, top, lane 4) and the 50 kilodalton La polypeptide (Fig. 6, bottom, lane 4 ) were present in the peak HPLC fractions containing the $\mathrm{Ro}^{\mathrm{hY} 5}$ RNPs, with the quantities of these proteins paralleling the peak of the $\mathrm{Ro}^{\mathrm{hY} 5}$ particles (compare Fig. $5 \mathrm{~A}$, lanes 5 and 7 to Fig. 6, lanes 4 and 5). These fractions lacked contaminating La RNAs, suggesting that the La polypeptide was stably associated with the $\mathrm{Ro}^{\mathrm{hY} 5}$ particles. As expected, both the $\mathrm{La}$ and the $60-\mathrm{kD}$ Ro polypeptides were present in the HPLC eluates containing the peak fractions of the $\mathrm{Ro}^{\mathrm{hY} 1-\mathrm{hY} 4}$ and the Ro ${ }^{\text {hY4 }}$ RNPs (data not shown), since these fractions contained both Ro and La RNAs.

Of note, the La polypeptide in the HPLC eluates was predominantly composed of the intact 50 kilodalton molecule, with minimal degradation (Fig. 6, bottom, lanes 1, 2, 4, and 5), compared to degradation of contaminating La protein in the immunoaffinity-purified Ro polypeptide preparation (Fig. 6, bottom, lane 3). Similar results were obtained with immunoblots of the HPLC eluates containing the peak fractions of the $\mathrm{Ro}^{\mathrm{hY} 1-\mathrm{hY} 4}$ and the $\mathrm{Ro}^{\mathrm{hY} 4} \mathrm{RNPs}$ (data not shown). Since the La polypeptide is highly sensitive to protease (26), this indicated that the Ro particles purified under our conditions were not substantially degraded.

To investigate more precisely the protein constituents of the HPLC-purified, intact $\mathrm{Ro}^{\mathrm{hYS}}$ particles, we immunoprecipitated the peak fraction using antibodies specific for the $60-\mathrm{kD}$ 

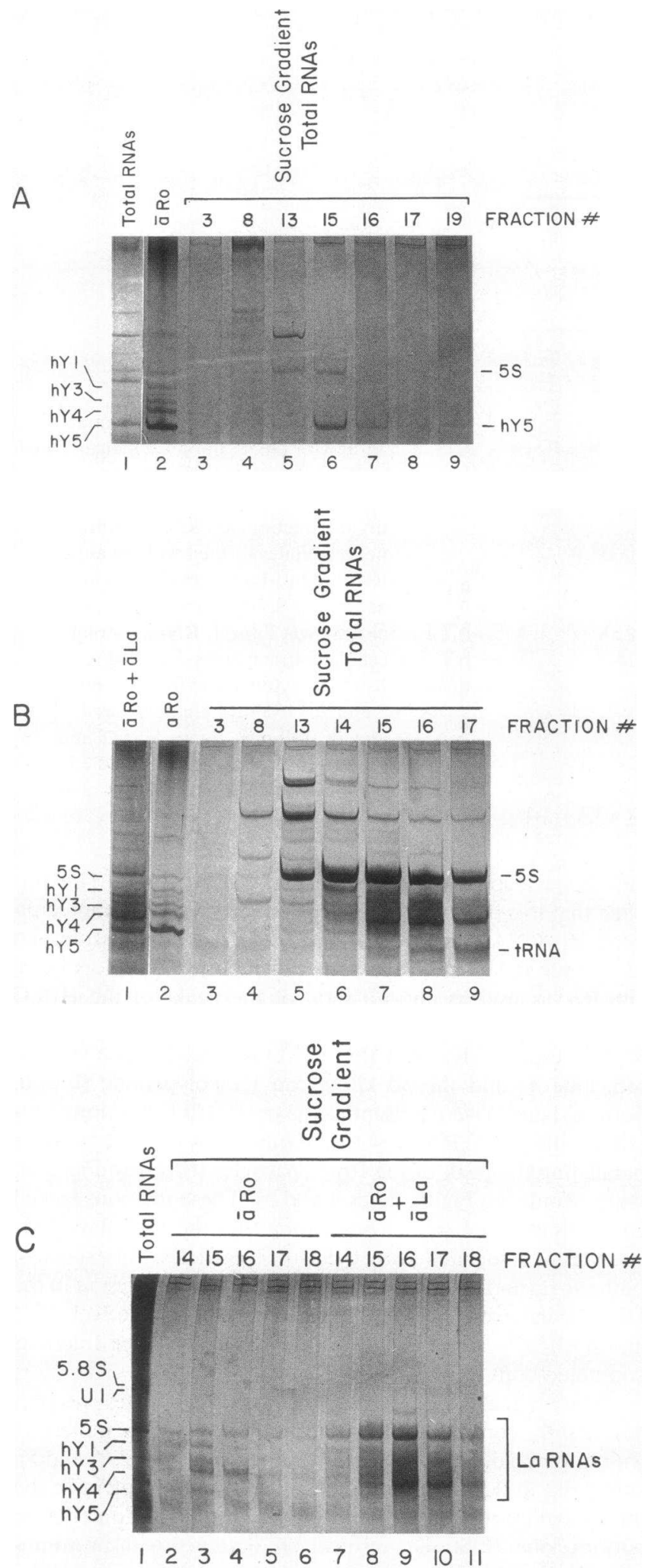

Figure 3. Sucrose gradient rate zonal ultracentrifugation of Ro RNPs. $(A)$ Total RNAs present in successive fractions of the gradient of the $175 \mathrm{mM}$ DE52 eluate. Lane 1 shows total RNAs present in the $175 \mathrm{mM}$ eluate from DE52, and lane 2 shows an immunoprecipitate of a HeLa cytoplasmic extract using a control anti-Ro serum to help identify the Ro RNAs. Successive fractions (1-22) were collected from the bottom of the tube; total RNAs present in representative fractions are shown. $(B)$ Total RNAs present in successive frac-

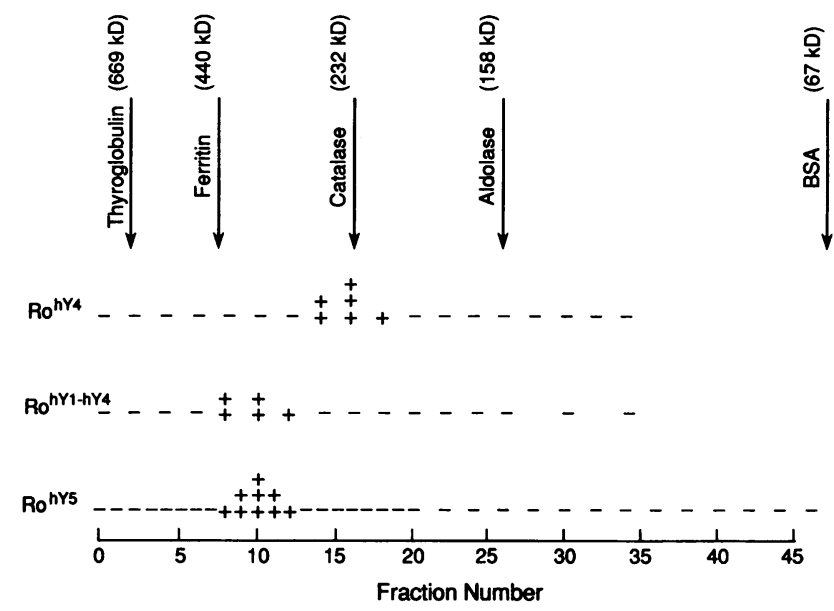

Figure 4. HPLC gel filtration of the fractions from the sucrose gradients containing the peaks of Ro particles. The elution profile of molecular weight standards is shown (BSA, bovine serum albumin). The abscissa shows fraction number (see Methods for details). The elution profiles of the $\mathrm{Ro}^{\mathrm{hY} 5}, \mathrm{Ro}^{\mathrm{hY} 4}$, and the $\mathrm{Ro}^{\mathrm{hY} 1-\mathrm{hY} 4}$ particles are shown on the ordinate as - to +++ , where - is undetectable by immunoprecipitation, + is barely detectable, ++ is clearly detectable, and +++ is the maximum intensity. Blank spaces indicate that a particular fraction was not tested by immunoprecipitation.

Ro polypeptide and the La polypeptide, respectively; antibodies that selectively immunoprecipitated the $\mathrm{Ro}^{\text {hYs }}$ particle from crude cell extracts (19) were also used in these experiments. As shown in Fig. 7, lanes 2, 3, and 5, these three antibodies immunoprecipitated the $\mathrm{Ro}^{\text {hYS }}$ particle. Since the $\mathrm{Ro}^{\mathrm{hY} \mathrm{Y}-\mathrm{hY} 4}$ and the $\mathrm{Ro}^{\mathrm{hY} 4}$ fractions were contaminated with La RNPs, a similar immunoprecipitation of these purified particles was not attempted.

\section{Discussion}

We have partially purified Ro particles from HeLa cells that appear immunologically and biochemically intact, without significant degradation of the RNA or protein components. These particles likely exist as distinct populations of RNPs, since they partitioned into three subgroups, $\operatorname{Ro}^{\mathrm{hY} 1-\mathrm{hY} 4}, \mathrm{Ro}^{\mathrm{hY} 4}$, and $\mathrm{Ro}^{\mathrm{hYS}}$, with at least the latter fraction being stably associated with the La polypeptide.

Several lines of evidence indicate that the Ro RNPs purified during these studies were intact. First, the RNA components of the purified RNPs did not degrade during the purification, since their electrophoretic mobility remained constant and identical to that of freshly immunoprecipitated Ro RNAs. Second, immunoblots of the final HPLC eluates indicated that the 60-kD Ro polypeptide, as well as the protease-sensitive $\mathrm{La}$ polypeptide, were largely intact. Thirdly, the autoantigenic

tions of the gradient of the $250 \mathrm{mM}$ DE52 eluate. Lane 1 shows the immunoprecipitated control La RNAs and lane 2 shows immunoprecipitated control Ro RNAs, both from a cytoplasmic extract. Successive fractions were collected from the bottom of the tube. $(C) \mathrm{Im}$ munoprecipitates of the fractions of a gradient of the $250 \mathrm{mM}$ DE52 eluate using control anti-Ro (lanes 2-6) and anti- $\mathrm{La}$ (lanes 7-11) sera. The fractions correspond to those in $\mathrm{B}$. 

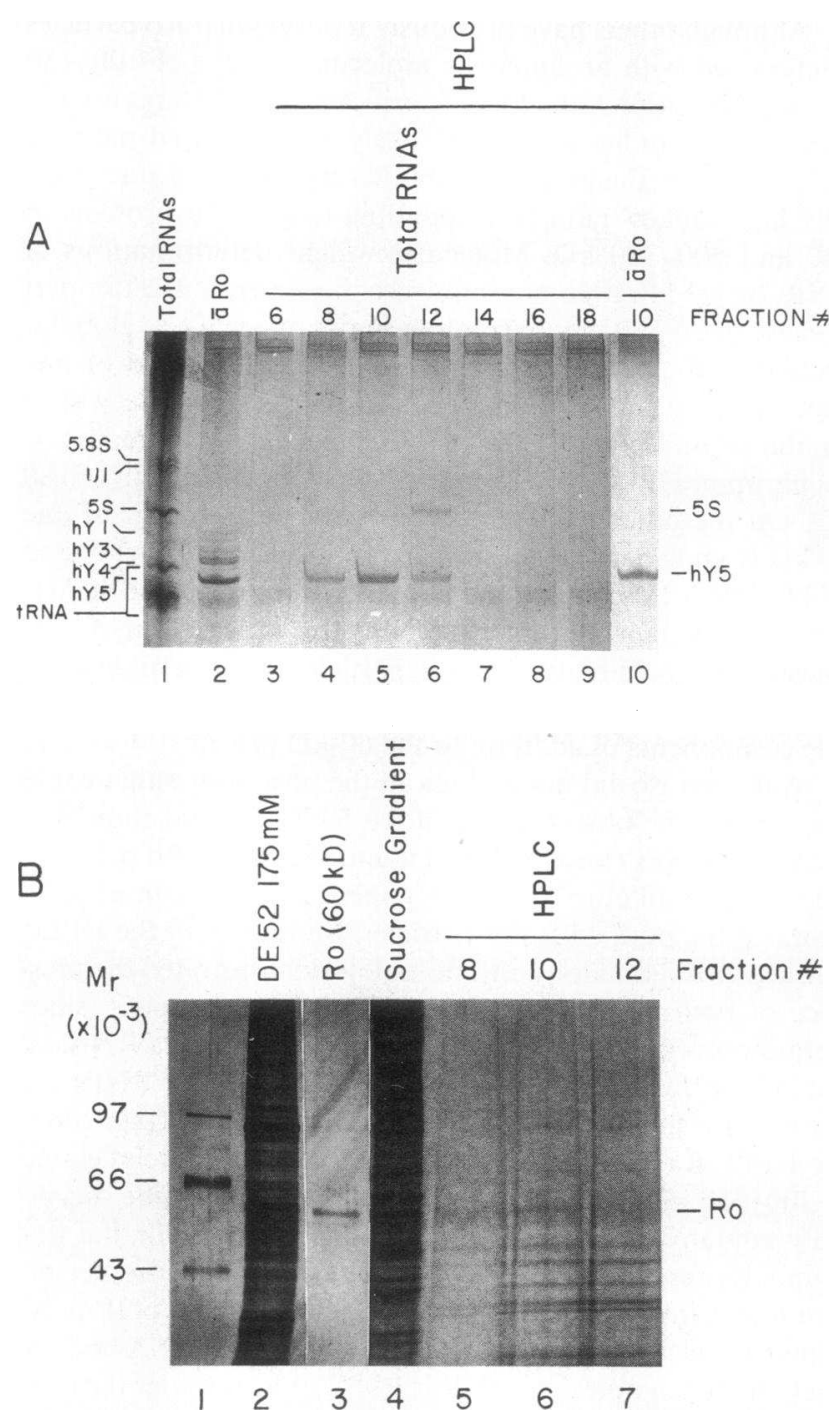

Figure 5. HPLC purified $\mathrm{Ro}^{\mathrm{hYS}}$ particles. $(A)$ Total RNAs present in successive fractions from the HPLC gel filtration column containing the purified $\mathrm{Ro}^{\mathrm{hY} 5}$ particles. Lane 1 shows total RNAs present in cytoplasmic extracts and lane 2 shows the control Ro RNAs immunoprecipitated from these extracts. The fractions were numbered from the first fraction eluted after the dead volume of the column. Lane 10 shows the RNAs immunoprecipitated from fraction 10 using a control anti-Ro serum. (B) Silver-stained SDS-polyacrylamide gel showing the proteins present in the $175-\mathrm{mM} \mathrm{NaCl}$ eluate from DE52 column (lane 2), the peak $\mathrm{Ro}^{\mathrm{hY}}$ fraction in the sucrose gradient (lane 4), and the peak $\mathrm{Ro}^{\text {hYs }}$ fractions in HPLC gel filtration (lanes 5-7). Extracts loaded in each lane were derived from approximately equal numbers of cells. Lane 3 illustrates $60 \mathrm{kD}$ Ro polypeptides affinity purified from human placenta.

60-kD Ro polypeptide remained complexed with its RNAs throughout the steps of purification, since Ro RNAs could be immunoprecipitated with anti-Ro sera; similarly, the La polypeptide remained stably associated with the $\mathrm{Ro}^{\text {hY } 5}$ particle since it was immunoprecipitable with an affinity-purified anti-La serum. Finally, the conformation-dependent antigenic determinant specific to the $\mathrm{Ro}^{\mathrm{hY} 5}$ particle was still intact since these particles could be immunoprecipitated with an anti$\mathrm{Ro}^{\text {hY5 }}$ serum.
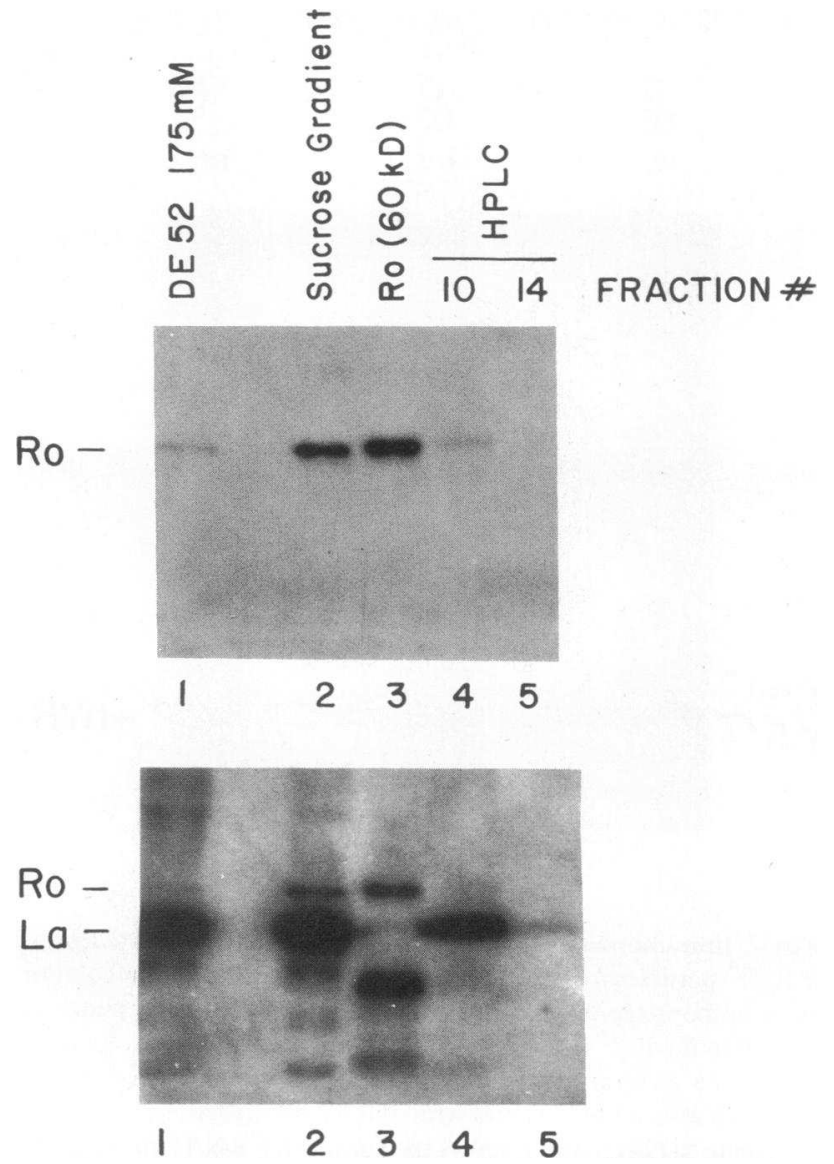

Figure 6. Immunoblots of $\mathrm{Ro}^{\mathrm{hYS}}$ particles after HPLC fractionation. Upper panel. The nitrocellulose sheet was incubated with an anti-Ro serum (1:100). Lower panel. The nitrocellulose sheet from panel A was reprobed with a strong anti-La serum (1:200). In each panel, lane 1 represents the $175 \mathrm{mM} \mathrm{NaCl}$ eluate from a DE52 column, lane 2 represents the peak of the sucrose gradient for the eluate from the DE52 column, lane 3,60 kD Ro polypeptides affinity-purified from human placenta, lane 4 shows the peak of the $\mathrm{Ro}^{\mathrm{hYS}}$ particles eluted from HPLC gel filtration, and lane 5 shows a fraction collected after the $\mathrm{Ro}^{\mathrm{hY} 5}$ peak.

Previous studies have concentrated upon purification of the protein component of the Ro RNPs, either biochemically $(27-29)$, or by affinity purification (30); in both cases, the conditions of purification made it unlikely that intact ribonucleoprotein particles could be purified. The recent identification of anti-Ro antibodies, that are apparently restricted to intact $\mathrm{Ro}^{\mathrm{hY} 5}$ particles (19), as well as the discovery of other autoantibodies that target conformational epitopes $(31,32)$, indicates that isolated RNPs containing their cognate RNAs will be useful in further analysis of the humoral autoimmune response.

In extension of our previous immunological and biochemical observations suggesting that the Ro particles are heterogeneous (19), sensitivity to salt disruption was uneven among these RNPs: the $\mathrm{Ro}^{\mathrm{hY} 4}$ and $\mathrm{Ro}^{\mathrm{hY} 3}$ RNAs began to dissociate from their autoantigenic polypeptide at $250 \mathrm{mM} \mathrm{NaCl}$, with the $\mathrm{Ro}^{\mathrm{hY} 1}$ and $\mathrm{Ro}^{\mathrm{hY} 5}$ RNPs being somewhat more resistant to disruption in high salt. Binding of all four Ro RNAs to the 60-kD Ro polypeptide was totally disrupted in buffers of rela- 


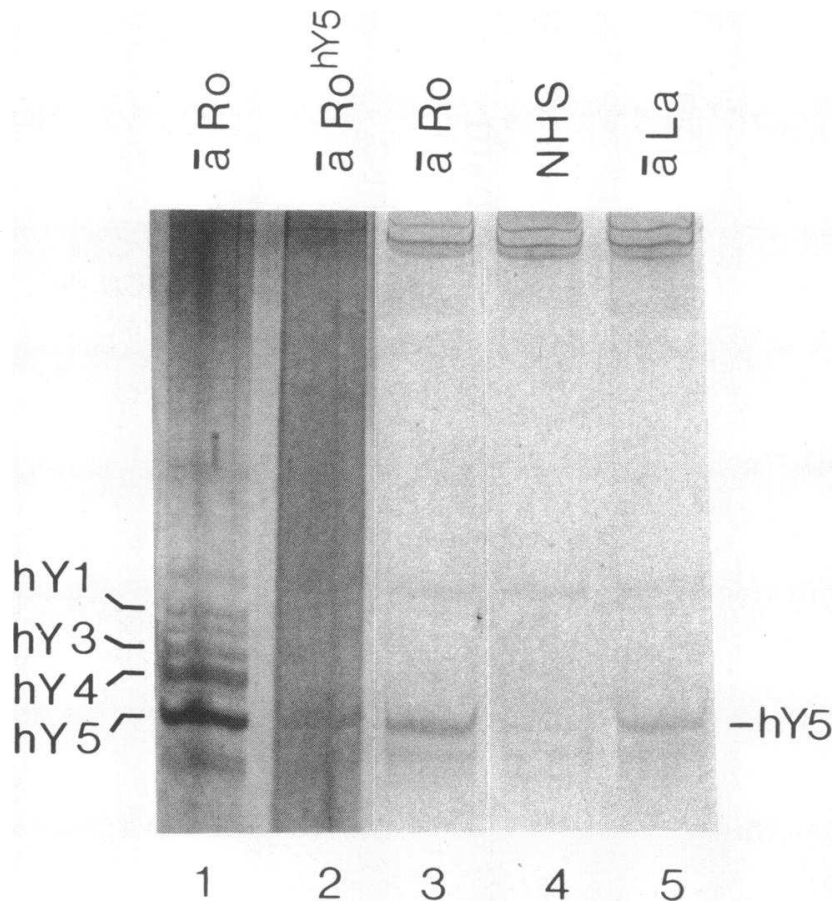

Figure 7. Immunoprecipitation of HPLC-purified $\mathrm{Ro}^{\text {hY5 }}$ particles. The $\mathrm{Ro}^{\mathrm{hY5}}$ particles from the peak of the HPLC gel filtration column were immunoprecipitated with $10 \mu \mathrm{l}$ of sera specific for an epitope restricted to the $\mathrm{Ro}^{\mathrm{hY} 5}$ particle (19) (lane 2), or the 60-kD Ro polypeptide (lane 3); immunoprecipitates were also formed with a normal human serum (lane 4) and with affinity-purified anti-La antibodies (lane 5) (24). Lane 1 shows the control Ro RNAs immunoprecipitated from a HeLa cytoplasmic extract using the same anti-Ro serum shown in lane 3 .

tively low ionic strength $(500 \mathrm{mM} \mathrm{NaCl})$, a characteristic shared by many nucleic acid binding proteins (33). Conversely, the binding of the La RNAs to the La protein did not appear to be affected by exposure to buffers containing up to $750 \mathrm{mM} \mathrm{NaCl}$. Thus, interactions of these two proteins with their respective RNAs are likely to be quite different, even if they appear to be present simultaneously on the same ribonucleoprotein particles, as previously shown $(28,29,34)$, and as confirmed in our studies.

Heterogeneity of Ro particles was further substantiated during purification, since three populations of these RNPs were obtained that differed in discrete biochemical properties. The first population containing the hY5 RNA ( $\mathrm{Ro}^{\mathrm{hYS}}$ particles) eluted from an anion-exchanger at low salt, sedimented in sucrose gradients somewhat faster than the La RNPs, and had a Stokes' radius compatible with a globular protein of 300 to $350 \mathrm{kD}$. A second one enriched in $\mathrm{Ro}^{\mathrm{hY} 4} \mathrm{RNPs}$ eluted from DE52 at higher salt, sedimented in sucrose gradients with the La RNPs, and had an apparent molecular weight of $\sim 230$ kD. Finally, a group of particles containing the hY $1, h Y 3$ and hY4 RNAs (Ro ${ }^{\text {hY1-hY4 }}$ RNPs) eluted at an intermediate salt concentration, sedimented in sucrose gradients ahead of the La RNPs, and had an apparent molecular weight of 300 to 350 $\mathrm{kD}$. At present we are unsure if this latter group of particles consist of individual Ro RNPs with similar physical properties, or if they exist as a complex.
Although others have previously reported that Ro particles fractionated with an apparent molecular weight of 100-150 $\mathrm{kD}$ in gel filtration $(30,35)$, the purification procedures used in these earlier studies made it unlikely that the sized particles were intact. In the current study, Ro particles had unexpectedly high Stokes' radii corresponding to globular proteins of 230 and $300-350 \mathrm{kD}$. Molecular weight determinations of RNPs by gel filtration are imprecise, however, at least in part because these particles in solution may not behave as globular proteins (36). For example, the 7S RNP, comprised of one copy each of the 5S RNA and a 34-kD polypeptide with a combined molecular weight of $73 \mathrm{kD}$, has a Stokes' radius by gel filtration HPLC corresponding to a globular protein of 120 $\mathrm{kD}$. On the other hand, the actual molecular weight of one 60-kD Ro polypeptide plus one Ro RNA ( $27 \mathrm{kD}$ for hY5, and $37 \mathrm{kD}$ for hY 1) is similar to that of the 7S RNP, yet the Stokes' radius is much greater for Ro RNPs; this observation at least suggests the possibility that Ro particles or their individual components exist as multimers, or that they contain polypeptide components in addition to the $60-\mathrm{kD}$ protein.

Although we did not address all the possibilities that could account for the observed size of Ro RNPs, we did show that the $\mathrm{Ro}^{\mathrm{hY} 5} \mathrm{RNPs}$ contained the $\mathrm{La}$ and the $60-\mathrm{kD}$ Ro polypeptides since antibodies specific for these proteins immunoprecipitated the purified $\mathrm{Ro}^{\mathrm{hY} 5}$ particles. Moreover, in the HPLC purified $\mathrm{Ro}^{\mathrm{hY}}$ fractions, immunoblots demonstrated the presence of both the La and the 60-kD Ro polypeptides; since immunoprecipitates of these fractions lacked the La RNAs, it did not seem likely that contamination with La RNPs accounted for the presence of the La polypeptide. Further, since the HPLC fraction that was enriched in $\mathrm{Ro}^{\mathrm{hY} 5}$ particles eluted at $300-350 \mathrm{kD}$, it is unlikely that free La polypeptide specifcally contaminated this fraction and accounted for the immunoblot results (Fig. 6, bottom). Thus, the immunoprecipitation and immunoblot experiments indicate that both polypeptides are capable of associating with the hY5 RNA and are likely stably complexed with this RNA, at least under the conditions utilized in this study. To account for the $300-\mathrm{kD}$ molecular weight of the $\mathrm{Ro}^{\mathrm{hY5}} \mathrm{RNPs}$, however, these particles may exist as dimers. At present, we do not know if the newly described $52 \mathrm{kD}$ Ro polypeptide (13) is also a constituent of these purified RNPs, as the sera we used as probes in these studies only targeted the La and the $60-\mathrm{kD}$ Ro proteins.

It is unclear if the other populations of Ro RNPs $\left(\mathrm{Ro}^{\mathrm{hY} 1-\mathrm{hY} 4}\right.$ and $\mathrm{Ro}^{\mathrm{hY}}{ }^{\mathrm{R}} \mathrm{RNS}$ ) are stably associated with the La polypeptide. These fractions were contaminated with the La RNPs and immunoprecipitation and immunoblotting experiments with anti-La antibodies were obscured by this contamination; however, the size of these particles ( $>220 \mathrm{kD}$ ) suggest that they are composed of more than one copy of the $60-\mathrm{kD}$ Ro polypeptide and more than one 30-kD RNA.

Certain observations suggest that the La polypeptide may have a unique relationship with $\mathrm{Ro}^{\text {hY5 }}$ RNPs. For example, under conditions where all Ro RNAs were dissociated from the 60-kD Ro polypeptides (Fig. $1 A$, lane 2), anti-La antibodies still immunoprecipitated a fraction of the hY5 RNAs, but none of the hY1 and hY2 RNAs (Fig. $1 A$, lane 7). Similarly, we also have observed that immunoprecipitates of total HeLa cell extracts using affinity-purified anti-La antibodies show a clear hY5 band but no hY1 or hY2 RNAs (hY3 and hY4 are obscured by the very abundant La RNAs). 
It is significant that among all mature, processed RNA polymerase III transcripts, Ro RNAs (or a portion of these RNAs such as hY5) are the only ones stably associated with the La polypeptide, and that these RNAs are the RNA polymerase III transcripts still produced in cells grown under adverse conditions (11). It thus follows that the function of Ro RNPs may be related to that of the La polypeptide, which is thought to serve as a terminator of RNA polymerase III transcription (17, 18). Ro RNPs could serve as a cofactor that modulates La activity, or as a "sink" to help recycle used La polypeptides for another round of transcription termination. Alternatively, Ro RNPs bearing the La polypeptide could contain incompletely processed Ro RNAs $(17,18)$; however, this latter possibility appears less likely since no difference in mobility of the hY5 RNA can be detected when Ro ${ }^{\text {hYS }}$ RNPs are immunoprecipitated with either anti-Ro or anti-La antibodies.

Antibodies specific for the $60-\mathrm{kD}$ Ro and the La polypeptides frequently occur in tandem, or as a linked set $(4,10)$. The close proximity and the stable association of these two polypeptides on at least a subset of the Ro RNAs provide a potential macromolecular target for this linked autoantibody set, and thus favors the hypothesis that autoantigens drive immune responses in SLE and related illnesses (4).

In conclusion, both protein and RNA components have been shown to be essential for complete function of certain other RNP autoantigens (37-39). Thus, intact Ro particles such as those obtained in these experiments may represent reagents to study the activity of this RNP, either alone or in conjunction with the La polypeptide, perhaps in the regulation of transcription by RNA polymerase III.

\section{Acknowledgments}

We are very grateful to Dr. John Hardin (Yale University School of Medicine) for invaluable discussions, support, and review of the manuscript. We also thank Dr. H. A. Menard (Centre Hospitalier Universitaire de Sherbrooke) for sera, and Dr. M. J. Mamula (Yale University School of Medicine) for helpful discussions, review of this work, and affinity-purified human 60-kD Ro polypeptides.

This work was supported by grants from the National Institutes of Health (AI-26853 to J. Craft, AR-32549 to Dr. John Hardin), the United Scleroderma Foundation (to J. Craft), the Arthritis Foundation and its Connecticut Chapter, and the Lupus Foundation of America. Dr. Boire is a recipient of Arthritis Society Postdoctoral Fellowship FC 13-27-(87). Dr. Craft is a Pew Scholar in the Biomedical Sciences.

\section{References}

1. Tan, E. M. 1982. Autoantibodies to nuclear antigens (ANA): their immunobiology and medicine. Adv. Immunol. 33:167-240.

2. Hardin, J. A., and T. Mimori. 1985. Autoantibodies to ribonucleoproteins. Clin. Rheum. Dis. 11:485-505.

3. Tan, E. M., E. K. L. Chan, K. F. Sullivan, and R. L. Rubin. 1988. Antinuclear antibodies (ANAs): diagnostically specific immune markers and clues toward the understanding of systemic autoimmunity. Clin. Immunol. Immunopathol. 47:121-141.

4. Hardin, J. A. 1986. The lupus autoantigens and the pathogenesis of systemic lupus erythematosus. Arthritis Rheum. 29:457-460.

5. Sturgess, A. D., M. G. Peterson, L. J. McNeilage, S. Whittingham, and R. L. Coppel. 1988. Characteristics and epitope mapping of a cloned human autoantigen La. J. Immunol. 140:3212-3218.
6. Van de Water, J., M. E. Gershwin, P. Leung, A. Ansari, and R. L. Coppel. 1988. The autoepitope of the 74-kD mitochondrial autoantigen of primary biliary cirrhosis corresponds to the functional site of dihydrolipoamide acetyltransferase. J. Exp. Med. 167:1791-1799.

7. Deutscher, S. L., J. B. Harley, and J. D. Keene. 1988. Molecular analysis of the 60-kDa human Ro ribonucleoprotein. Proc. Natl. Acad. Sci. USA. 85:9479-9483.

8. Query, C. C., and J. D. Keene. 1987. A human autoimmune protein associated with U1 RNA contains a region of homology that is cross-reactive with retroviral p30sag antigen. Cell. 51:211-220.

9. Reichlin, M. 1986. Significance of the Ro antigen system. $J$. Clin. Immunol. 6:339-348.

10. Harley, J. B., E. L. Alexander, W. B. Bias, O. F. Fox, T. T. Provost, M. Reichlin, H. Yamagata, and F. C. Arnett. 1986. AntiRo(SS-A) and anti-La(SS-B) in patients with Sjogren's syndrome. $A r$ thritis Rheum. 29:196-206.

11. Hendrick, J. P., S. L. Wolin, J. Rinke, M. R. Lerner, and J. A. Steitz. 1981. Ro small cytoplasmic ribonucleoproteins are a subclass of La ribonucleoproteins: further characterization of the Ro and La small ribonucleoproteins from uninfected mammalian cells. Mol. Cell. Biol. 1:1138-1149.

12. Wolin, S. L., and J. A. Steitz. 1984. The Ro small cytoplasmic ribonucleoproteins: identification of the antigenic protein and its binding site on the Ro RNAs. Proc. Natl. Acad. Sci. USA. 81:1996-2000.

13. Ben-Chetrit, E., E. K. L. Chan, K. F. Sullivan, and E. M. Tan. 1988. A 52-kD protein is a novel component of the SS-A/Ro antigenic particle. J. Exp. Med. 167:1560-1571.

14. Rader, M. D., C. O'Brien, Y. Liu, J. Harley, and M. Reichlin. 1989. Heterogeneity of the Ro/SSA antigen: Different molecular forms in lymphocytes and red blood cells. J. Clin. Invest. 83:1293-1298.

15. Wolin, S. L., and J. A. Steitz. 1983. Genes for two small cytoplasmic Ro RNAs are adjacent and appear to be single-copy in the human genome. Cell. 32:735-744.

16. Stefano, J. E. 1984. Purified lupus antigen La recognizes an oligouridylate stretch common to the $3^{\prime}$ termini of RNA polymerase III transcripts. Cell. 36:145-154.

17. Gottlieb, E., and J. A. Steitz. 1989. The RNA binding protein La influences both the accuracy and the efficiency of RNA polymerase III transcription in vitro. EMBO (Eur. Mol. Biol. Organ.) J. 8:841850.

18. Gottlieb, E., and J. A. Steitz. 1989. Function of the mammalian La protein: evidence for its action in transcription termination by RNA polymerase III. EMBO (Eur. Mol. Biol. Organ.) J. 8:851-862.

19. Boire, G., and J. Craft. 1989. Biochemical and immunological heterogeneity of the Ro ribonucleoprotein particles. Analysis with sera specific for the $\mathrm{Ro}^{\text {hYS }}$ particle. J. Clin. Invest. 84:270-279.

20. Craft, J., T. Mimori, T. L. Olsen, and J. A. Hardin. 1988. The U2 small nuclear ribonucleoprotein particle as an autoantigen: analysis with sera from patients with overlap syndromes. J. Clin. Invest. 81:1716-1724.

21. Forman, M. S., M. Nakamura, T. Mimori, C. Gelpi, and J. A. Hardin. 1985. Detection of antibodies to small nuclear ribonucleoproteins and small cytoplasmic ribonucleoproteins using unlabeled cell extracts. Arthritis Rheum. 28:1356-1361.

22. Laemmli, U. K. 1970. Cleavage of structural proteins during the assembly of the head of bacteriophage T4. Nature (Lond.). 227:680-685.

23. Towbin, H., T. Staehelin, and J. Gordon. 1979. Electrophoretic transfer of proteins from polyacrylamide gels to nitrocellulose sheets: procedure and some applications. Proc. Natl. Acad. Sci. USA. 76:4350-4354.

24. Smith, D. E., and P. A. Fisher. 1984. Identification, developmental regulation, and response to heat shock of two antigenically related forms of a major nuclear envelope protein in Drosophila embryos. Application of an improved method for affinity purification of antibodies using polypeptides immobilized on nitrocellulose sheets. $J$. Cell Biol. 99:20-28. 
25. Kato, N., H. Hoshino, and F. Harada. 1982. Nucleotide sequence of 4.5S RNA (C8 or hY5) from HeLa cells. Biochem. Biophys. Res. Commun. 108:363-370.

26. Habets, W. J., J. H. den Brok, A. M. Th. Boerbooms, L. B. A. van de Putte, and W. J. van Venrooij. 1983. Characterization of the SS-B (La) antigen in adenovirus-infected and uninfected HeLa cells. EMBO (Eur. Mol. Biol. Organ.) J. 2:1625-1631.

27. Lieu, T. S., M. Jiang, J. C. Steigerwald, and E. M. Tan. 1984. Identification of the SS-A/Ro intracellular antigen with autoimmune sera. J. Immunol. Methods. 71:217-228.

28. Elkon, K. B., and L. Culhane. 1984. Partial immunochemical characterization of the Ro and La proteins using antibodies from patients with the sicca syndrome and lupus erythematosus. J. Immunol. 132:2350-2356.

29. Deng, J. S., R. D. Sontheimer, and J. N. Gilliam. 1985. Molecular characteristics of SS-B/La and SS-A/Ro cellular antigens. J. Invest. Dermatol. 84:86-90.

30. Yamagata, H., J. B. Harley, and M. Reichlin. 1984. Molecular properties of the Ro/SSA antigen and enzyme-linked immunosorbent assay for quantitation of antibody. J. Clin. Invest. 74:625-633.

31. Elkon, K., S. Skelly, A. Parnassa, W. Moller, W. Danho, H. Wessbach, and N. Brot. 1986. Identification and chemical synthesis of a ribosomal protein antigenic determinant in systemic lupus erythematosus. Proc. Natl. Acad. Sci. USA. 83:7419-7423.

32. Boire, G., S. Lapointe, F. J. Lopez-Longo, and H. A. Menard. 1988. Naturally occurring autoantibodies recognize conformational determinants on the Ro particles. Arthritis Rheum. 31:S67 (Abstr.).

33. Schleif, R. 1988. DNA binding by proteins. Science (Wash. DC). 241:1182-1187.

34. Eisenberg, R. A. 1985. Association between the Ro and La antigenic determinants: immunodiffusion analysis of human spleen extract. J. Immunol. 135:1707-1713.

35. Scopelitis, E., J. J. Biundo, and M. A. Alspaugh. 1980. AntiSS-A antibody and other antinuclear antibodies in systemic lupus erythematosus. Arthritis Rheum. 23:287-293.

36. Monteilhet, C., and L. P. Aggerbeck. 1986. High performance liquid chromatographic purification of a ribonucleoprotein complex and its protein component. Anal. Biochem. 154:162-170.

37. Sharp, P. A. 1987. Splicing of messenger RNA precursors. Science (Wash. DC). 235:766-771.

38. Altman, S. A., H. Gold, and M. Bartkiewicz. 1988. Ribonuclease $P$ as an snRNP. In Small Nuclear Ribonucleoproteins. M. Birnstiel, editor. Springer Publishing Corp., New York. 183-195.

39. Walter, P., and G. Blobel. 1983. Disassembly and reconstitution of signal recognition particle. Cell. 34:525-533. 